\title{
The Differential Effect of Team Members' Trust on Team Performance: The Mediation Role of Team Cohesion*
}

Merce Mach ${ }^{1}$, Simon Dolan ${ }^{1}$, and Shay Tzafrir ${ }^{2}$

${ }^{1}$ Institute for Labour Studies - IEL Research Centre, ESADE Business School - Ramon Llull University, Barcelona, Spain.

2 Department of Human Services, University of Haifa, Haifa, Israel. Visiting Professor at IEL Research Center, ESADE Business School.

\section{$\underline{\text { Reference: }}$}

Mach, M.; Dolan, S.; Tzafrir, S. (2010). The Differential Effect of Team Members' Trust on Team Performance: The Mediation Role of Team Cohesion. Journal of Occupational and Organizational Psychology, 83(3): 771-794. (Available online: October 1, 2009).

*Requests for reprints should be addressed to Dr. Merce Mach, Av. Pedralbes 60-62, 08034 Barcelona, Spain (e-mail: merce.mach@esade.edu). 


\begin{abstract}
:
This study examines team performance as affected by various trusting relationships: Trust between team members and the team's trust in their direct manager and in top management. Data for the study were collected from a survey of 690 professional elite athletes (belonging to 59 different sports clubs) playing in the regular, top professional Spanish leagues. The model was tested at the team level. Findings reveal that team member trust with respect to the different foci has both a direct and indirect effect on team performance, and that team player trust and cohesion play a mediating role. This study illustrates the dynamic relationship within teams, and, as such, trust among teammates mediates the relationship between trust in the coach as well as team cohesion in determining team performance. The implications for managing teams in other contexts are also evaluated.
\end{abstract}

\title{
Key words:
}

Team trust; team performance; team cohesion. 


\section{The Differential Effect of Team Members' Trust on Team Performance: The Mediation Role of Team Cohesion}

During the entire last season two words have been unavoidable when referring to the Barcelona Football Club (also known as Barça): "Dream" and "team." In the build-up to the Champions League final match, Pep Guardiola, the team's young coach, was asked if, in a roundabout sort of way, it didn't matter if Barcelona lost. "Of course it matters!", he replied. "We have to think it is absolutely fundamental to win; Manchester United is the best team in the world, thus, if you go there thinking that this is not a big deal, then there is a 100\% chance of losing. Yes, we have had a great season [they won all the tournaments they participated in], but we want to show the world how we have been playing! I don't have a method. I have good players. I would not be in the final without these players. They are the team!. And most important, they trust very much in what they are going to do," said Guardiola (Millward, 2009; The Guardian, 2009).

As shown in this opening statement, trust is highly beneficial to the functioning of an organization (Kramer, 1999; Lewicki, McAllister, \& Bies, 1998). By and large, research has suggested a link between trust and a variety of work behaviour including: Organizational citizenship behaviour (Brower, Lester, Korsgaard \& Dineen, 2009; Konovsky, \& Pugh, 1994); employee performance, both individual and as a group (Dirks \& Skarlicki, 2009; Mayer, \& Davis, 1999); open communication (Smith, \& Barclay, 1997); a commitment to the team's objectives (Costa, Roe, \& Taillieu, 2001); team performance (Hempel, Zhang \& Tjosvold, 2009; Lawler, 1992); and increased coordination and cooperation (McAllister, 1995). Consequently, a stream of researchers has focused on ways and means to reinforce and intensify trust within organizations (i.e., Gambetta, 1988; McKnight, Cummings, \& Chervany, 1998, Dirks, \& Ferrin, 2002; Tzafrir, 2005). 
Albeit general consensus that trust enhances organizational relationships by increasing the ability of group members to work together (Mayer, Davis, \& Schoorman, 1995; McAllister, 1995), the findings that specify exactly why trust is expected to enhance team performance are far from reaching consensus. Prior research on working teams has demonstrated a positive relationship between trust and performance (Costa et al., 2001; Schippers, 2003) although this relationship has not always been significant (Aubert, \& Kelsey, 2003). Studies on the relationship between team trust and performance have yielded inconsistent results (Dirks, 1999; Langfred, 2004). For instance, Dirks' study of 42 experimental group projects found that trust influenced group processes and performance indirectly and that groups with higher levels of trust did not necessarily perform better than groups with lower levels of trust (Dirks, 1999). Rather, it was found that trust indirectly affected performance through other group processes. Langfred $(2004,2007)$ studied the performance of 111 teams and found that trust does not always lead to positive outcomes and that it could even act as a negative mechanism or have a dysfunctional effect depending on the situation. While these studies took into account team trust, they failed to address the issue of trust as a multifoci phenomenon in an organizational context.

In recent years, there has been increased interest in understanding team dynamics and the role of interpersonal and organizational trust (Carron, Colman, Wheeler \& Stevens, 2002; Mullen \& Copper, 1994). Trust is an integral part of teamwork because team tasks require a high level of interdependence between members. This mutual dependency may generate synergy in the form of cooperation and interaction amongst team members (De Vries, 1999; Fiore, Salas \& CannonBowers, 2001) and, subsequently, it may explain variations in team performance. The sports world offers a wide range of examples of teams that work well together and teams that do not (Katz, 2001). If we consider the large amount of money and resources invested in this sector, it is not difficult to imagine the great pressure placed on professional sports teams. Players need to perform 
well from the beginning and maintain a high level of performance until the end of the season. Thus, professional sports teams provide an ideal context to explore the manifestations of group dynamics and their relationship to performance. To analyze trust within organizations that are structured as a team, the context of professional sports provides an excellent opportunity to examine these factors because sports teams have a self-contained nature and clear performance outcomes.

In this sense, observers of the sporting world (Turman, 2003) often ask why a team that has successfully performed one year may not repeat the same success the following season or vice versa. How is it that, against all logic, a team whose members seem less capable can become the league champions? How can we explain these contrasting results? Can differences in a team's performance be explained by the trust relationships and cohesion between its members, management and the organization? The literature is not completely clear whether performance affects cohesion or if team cohesion and trust stimulate good performance. Only limited results have been obtained through empirical research (e.g., Carron, \& Bray, 2002; Fontayne, Heuze, \& Raimbault, 2006).

The purpose of our research is to examine how the multiple targets of trust affect team performance (namely: trust amongst members of the team, trust in the direct supervisor, coach or manager, and trust in top management). We also explore the mediating role team cohesion plays in the relationship between team trust and team performance.

\section{Theory and Hypotheses}

A careful review of the management literature on trust reveals that there has been little consensus among scholars to settle on a single working definition of trust (Kramer, 1999; Rousseau, Stikin, Burt, \& Carmerer, 1998). While the broad definition is debatable, there does seem to be stronger consensus regarding the conditions for trust. Tzafrir and Dolan (2004) summarized that three 
conditions might clarify the point of mutuality in trust-based relations. The first condition is vulnerability, which involves the uncertainty of the future and the willingness of the parties to take a risk. The second is previous mutual interactions, which are perceived by the parties as positive and reciprocal. The third condition involves expectations over time regarding reliable conduct. Lewicki, Tomlinson, and Gillespie's (2006) summary of various models of interpersonal trust concluded that trust from a psychological perspective (Rousseau et al., 1998) is a mental state that implies positive expectations regarding the other party's intentions and behaviour. In this respect, the act of trusting reflects a willingness to accept vulnerability from the trustor's perspective, and an expectation that the other party, the trustee, will reciprocate trustworthily (Dietz \& Den Hartog, 2006).

Rousseau et al. (1998) assert that trust involves individual processes, group dynamics and organizational or institutional contingencies simultaneously. Thus, trust may be conceptualized differently depending upon the level at which the data are aggregated (between individuals, groups, systems, organizations, etc.). The literature on trust also emphasizes different foci of trust within different levels of analysis. Roter (1971) focuses his definition of trust at the individual level, while Mayer et al. (1995) establish a dyadic model. Moreover, Zucker (1986) focuses on institutional trust in her seminal work. These arguments may be the main reason for Lane's (1998) suggestion that any theory on trust needs to incorporate its "multidimensional social reality," possibly serving as a bridge between the micro and macro levels (Lewis, \& Weigert, 1985). For this reason, trust is considered a "mezzo" concept given that it integrates psychological and group dynamic processes at the micro level and organizational and institutional forms at the macro level (Rousseau et al., 1998). When it is asserted that employees make judgments regarding the trustworthiness of their organization (Gillespie, \& Dietz, 2005), these employees are thinking about multiple actors, including their immediate work colleagues (Davis, Schoorman, Mayer, \& Tan, 2000), their 
managers (Mayer, \& Davis, 1999; Creed \& Milles, 1996), groups (Dirks, 1999; Costa, 2003), and the organization as a whole (Shockley-Zalabak, Ellis, \& Winograd, 2000).

\section{Team Trust, Cohesion and Exchange Theory}

According to Social Exchange Theory, organizations are forums for economic and social transactions (Cropanzano, Prehar, \& Chen, 2002). The distinction between social and economic exchanges is that "social exchanges entail unspecified obligations" (Blau, 1964, p. 93), they involve a series of interactions that generate obligations (Emerson, 1976), and they are usually seen as interdependent and contingent upon the actions of another person (Blau, 1964). Social exchange relationships evolve and generate beneficial consequences when employers "take care of employees." In this sense the social exchange relationship is a mediator or intervening variable that produces effective work behaviour and positive employee attitudes (Cropanzano, \& Mitchel, 2007).

Salas and Fiore (2004) assert that an effective team is expected to perform to an extent that is greater than the sum of the individuals' performance. This is especially true when team members perform a conjunctive and highly interdependent task, with a single output, and where the performance of the team is potentially measured by the poorest group member's performance along with that of the other teammates as occurs in interactive sports teams such as soccer, basketball and so on (Saavedra, Earley, \& Van Dyne, 1993). According to Social and Economic Exchange Theory, team effectiveness could result from interaction, coordination, and collaboration between the team members (Hackman \& Morris, 1975).

Furthermore, Social Exchange Theory explains social change as a process of negotiated exchanges between parties (Konovsky, \& Pugh, 1994). By seeing trust as a primary variable in these exchanges (Blau, 1964) and if we also consider the norm of reciprocity (Gouldner, 1960), we can understand the team's output. 
In our study, we attempt to examine the exchange through which trust in different organizational actors (other team players, the coach and the top management) translates into more effective behaviour that helps the team perform better through processes such as cohesion. Positive feelings and perceptions regarding one actor (e.g., the coach, teammates, and top management) as well as positive expectations about her/his goodwill engender an obligation on the part of employees to reciprocate (Lewis \& Weigrt, 1985). As such, a positive cycle of reinforcement takes place thanks to the dynamic relationship within the team. This implies the various actors being trustworthy while at the same time being open, reliable and concerned for others, something which can be seen in and lead to team cohesion.

Team cohesion is the degree to which team members work together as they pursue the team's goals. It is defined as "a dynamic process that is reflected in the tendency of a group to stick together and remain united in the pursuit of its instrumental objectives and/or for the satisfaction of member affective needs" (Carron, Brawley, \& Widmeyer, 1998, p. 213). Calnan and Rowe (2007) also discuss the importance of trust in creating team cohesion among healthcare teams. Hansen, Morrow, and Batista (2002), using 71 responses from two different marketing co-ops, found a consistently positive relationship between trust and group cohesion.

Based on these findings, we argue that the creation of cohesion among a team is strengthened when one member interprets another's words, attitudes, or actions as being reliable, honest, and containing genuine concern, thereby indicating a relationship of trust. This is in line with Mayer et al.'s (1995) idea that understanding trust and its causes can facilitate cohesion. For example, Grossman, Wineburg, and Woolworth (2001) conclude in their study on teachers that trust is one of the necessary elements to build cohesion. Similarly, Thau, Crossley, Bennett, and Sczesny (2007) conducted a field study of a Dutch healthcare organization and found that trust in organizations is related to workgroup cohesion. Another study (Luria, 2008) also found evidence linking leadership 
style and cohesion. In sports settings, several reports also corroborate this view. Gardner et al. (1996) and Westre and Weis (1991) found a significant relationship between coaching behaviour and group cohesion. Finally, Gilbert and Tang (1998) found in a US federal governmental agency study that group cohesion was positively associated to organizational trust. Consequently, the following hypotheses are advanced:

Hypothesis 1a: Trust in the coach is positively related to team cohesion.

Hypothesis 1b: Trust in teammates is positively related to team cohesion.

Hypothesis 1c: Trust in top management is positively related to team cohesion.

\section{Team Cohesion and Performance}

Weick and Roberts (1993) describe the effectiveness of a team as the result of the interrelated activities based on a given mentality or collective consciousness, where the members of the group see how their actions are interrelated. Due to the fact that interactive sports require a high level of task interdependence, highly cohesive teams show a significant relationship with performance (Carron et al., 2002; Mullen, \& Copper, 1994). A meta-analysis of team settings found that the relationship between cohesion and performance in sports teams is significant and stronger than in other working teams (Carron et al., 2002). It seems that highly cohesive groups tend to be more united and committed to success than groups with little cohesion. The explanation of why teams might perform better than the sum of the individual performers or why teams consisting of brilliant individual players might collectively underperform might be found in the role cohesion plays in linking group processes and team results; to rephrase, united groups will be able to use their capabilities more efficiently since they know their teammates better and they are committed to successfully finishing the task before them. There have been numerous studies describing the relationship between team cohesiveness and success. However, what these findings do not tell us is 
whether the teams studied were more successful because they were already more cohesive or whether, in fact, they became highly cohesive because they shared the experience of winning. It is quite possible that both of these are correct in light of the inconclusive findings from empirical studies. Some studies have addressed the connection between cohesion and performance in a variety of interactive sports. Slater and Sewell (1994), for example, measured team cohesion in hockey teams at different points of the season. They concluded that cohesiveness and success were mutually dependent and that the cohesion-performance relationship should be examined by means of a circular model in which cohesion and performance are interdependent. From Gould et al.'s (1999) study of Olympics athletes in different interactive sports, we see that teams with little cohesion were more likely to underperform, but that cohesiveness was just one of several important factors affecting performance. In an experimental study, other researchers (Grieve, Whelan, \& Meyers, 2000) did not find any relationship between cohesiveness before the games and performance. However, successful performance was associated with high levels of cohesiveness at the end of the games. Taking into account all these findings and looking at them through the lens of Social Exchange Theory and norms of reciprocity (Gouldner, 1960), reciprocal positive feelings between team members and towards the group as a whole lead to each individual contributing more towards group success. Thus, it is reasonable to hypothesize the following:

\section{Hypothesis 2: Team cohesion is positively related to team performance.}

According to McAllister, trust is defined as, "the point to which a person has confidence in another person and is prepared to act based on the words, deeds, and decisions of the other person or/and a group" (1995, p. 22). As such, colleagues that trust each other achieve better measures of performance, and the consequences of trusting behaviour may even extend beyond organizational purposes. Dirks (2000) demonstrated in his study of basketball teams that trust in the leader is 
related to team performance. The explained variance for trust was nearly equivalent to the explained variance for the team members' abilities. Furthermore, in a context like sports, where it might seem that trust in teammates is fundamental for success, Dirks and Ferrin (2002) found that trust in the manager is more closely related to work variables, while trust in top management is much more closely related to organizational variables due to the operative versus more strategic role coaches and management play respectively. Trust in top management and the organization appear to depend, to some extent, on the degree to which organizational systems produce trust (Creed, \& Milles, 1996). Several studies have found that trust in top management affects employee performance (Davis et al., 2000; Lo \& Aryee, 2003); we suggest that team cohesion intermediates this relationship.

Integrating social exchange and attribution theories, which are concerned with the ways in which people explain (or attribute) others' behaviours, helps us understand the role of cohesion as mediating the relationship between trust and team performance. Trust acts simultaneously along with belief and expectations regarding the behaviour of the other party. It also serves as an information source (attributional processes) for future obligations (norms of reciprocity). On the other hand, Simons and Peterson (2000) explore the importance of trust in the group process through its effect on interpretation mechanisms. The consistent arguments and findings in existing literature support the conclusion that cohesion may serve as a preliminary stage to actual behaviour (Hansen et al., 2002). It is reasonable, therefore, to conclude that cohesion mediates the relationship between trust and team performance because trust helps people to stick together and also because members of a cohesive group, a group with which they are identified and with which they have affinity, are more cooperative and willing to help each other (Mullen \& Copper, 1994). This argument is in line with findings revealing that team cohesion plays an important role in fomenting team performance (e.g., Carron et al., 2002; Beal, Cohen, Burke, \& McLendon, 2003). It accomplishes this by 
influencing the performance relationship processes (Barrick, Bradley, Kristof-Brown, \& Colbert, 2007) or by having a main effect (Chansler, Swamidass, \& Cammann, 2003). Other scholars report that cohesiveness functions as a mediator in the relationship between leadership, employee attitudes and performance (e.g., Loughead, Colman, \& Carron, 2001; Organ, Podsakoff, \& Mac Kenzie, 2006). Given the above, then, the third hypothesis of this study is:

Hypothesis 3: Team cohesion mediates the relationship between multifaceted trust and team performance.

Consistent with Whitener, Brodt, Korsgaard and Werner (1998) and others, this study focuses on the perceptions that employees have regarding interpersonal, group, and organizational trust, using the context of social exchange paradigms (Blau, 1964; Zucker, 1986). The conceptual framework for the study presented here is summarized in Figure 1.

Insert Figure 1 about here

\section{Methods and Procedures}

The data for the study were collected from a survey carried out among professional athletes (belonging to 59 different sports clubs) playing in the regular, top professional Spanish leagues (2004-2005 season): Basketball (ACB), handball (ASOBAL), roller hockey (OK-Liga), and indoor football (FNFS). Players were asked to complete a questionnaire after a training session held at the beginning of the second half of the regular season. Questionnaires were prepared following ten preliminary in-depth interviews with players, coaches, top managers, and scholars. In addition, twenty-five more interviews with team players were held to pre-test the survey questionnaire. Lastly, we organized a half-day focus group with fourteen experts, including academics and former and current professional players, coaches, and sports celebrities, to validate the proposed model. 
Performance indicators and control variables stem from additional independent sources (specialized sports databanks) and were collected for each team. Data on the criteria were gathered from independent sources in order to increase their reliability. Final results for the teams were obtained from the official league records. The study is based on a 'quasi-longitudinal design' (combining cross-sectional features for the independent variables with some longitudinal data for the dependent variable). A time lag of three months served to check whether the output exhibited differences in the results.

\section{Sample}

We chose interactive sports such as basketball, handball, indoor football, and roller hockey because they present similar features in terms of game rules and the degree of professionalism. Table 1 presents the general team profile for each sport. After all the teams in each professional Spanish league were mapped out, 778 players playing on 66 teams were approached to participate in the study. Of these, 690 professional players on 59 teams participated, resulting in an 89 percent response rate. The average size of teams was 11.7 members $(S D=2.3)$, the average age of the respondents was 25.5 years $(S D=1.6)$, the average tenure with the organization, 3.6 years $(S D=1.4)$, and the average tenure with their coach was 1.8 years $(S D=.9)$. The key characteristics tended to correspond to those of the sample population.

Insert Table 1 about here

\section{Statistical Analyses Strategy}

Before examining the relationship between trust and team performance, some preliminary analyses were conducted in order to check the psychometric properties of the measures (i.e., the internal reliability and consistency of the scales). These analyses were performed first at the individual 
level. Then, data was analyzed in different stages, employing different statistical techniques ranging from bivariate analyses (correlations and ANOVAs) in the first stage, to a series of multivariate analyses in the second stage, including Structural Equation Model testing.

All psychometric properties of the multi-item variables employed in this study were first tested at the individual level ( $n=690)$, and results were very satisfactory. We also checked whether or not there were significant differences between the different professional sports included in the sample. ${ }^{1}$ In reference to the preliminary analyses of the constructs, Confirmatory Factor Analyses (CFA) were performed at the individual level, while structural equation models and alternative model specifications were performed at the group level $(n=59)$.

Before aggregating the data into each group, several prior steps were taken. The average scores for the different team members were determined in keeping with Rousseau's recommendation (1985) to adjust the analysis level to the focus of the unit under study, in this case, the team. Team performance is a function, an aggregation, of the efforts of the entire team (Dirks, 1999). To determine whether or not we could justify aggregating individual responses to the team level, two statistical tests were employed. First, an Intra-Class Correlation (ICC) coefficient was calculated for all constructs of the model except for the control variables and performance (ranging from .82 to 93). The ICC compares within and between team variances using a one-way ANOVA test that assesses whether membership on a given team leads to more homogenous answers (McGraw, \& Wong, 1996). Second, an Inter-rater Agreement coefficient $\left(\mathrm{R}_{\mathrm{wg}}\right)$ was calculated based on James, Demaree, and Wolf's (1984) formula for multi-item constructs. It assesses variables at the team

\footnotetext{
${ }^{1}$ The results show that there were no significant differences between the dimensions presented in this study. Differences among the four teams were assessed using a one-way analysis of variance (ANOVA). A Levene Test of Homogeneity of Variance conducted prior to the ANOVA did not indicate that the assumption of homogeneity of variance was violated $(\mathrm{p}>.05)$ except for Trust in top management which was significant. Thus, the variances for the four sports samples are not equal for only that predictor. Additionally, a Brown-Forsythe Robust Test of Equality of Means was conducted for Trust in top management and the result was not significant: $\mathrm{F}(3,40.88)=.78, p=.515$, allowing us to assume from this analysis that such a single homogenous subset sample was applicable to all the predictor variables.
} 
level based upon answers given by individuals (Kozlowski \& Hattrup, 1992)) and determines whether there is some agreement among evaluators regarding a common target versus whether those ratings match a random pattern. This indicator ranges from 0 (complete disagreement) to 1 (complete agreement). The $\mathrm{R}_{\mathrm{wg}}$ estimate achieved acceptable levels, ranging from .71 to .82 , thus suggesting substantial agreement among raters.

Inspired by Wright, Gardner, and Moynihan, (2003), teams were randomly split into two parts. As such, we eliminated the possibility of within-person common method variance on perceptpercept correlations which can be biased by collecting different measures from the same source and using the same method at the same time. In all subsequent analyses, we gathered information on multi foci trust (in teammates, coaches and top management) from half of the players and information on team cohesion from the other half.

\section{Measures:}

\section{Dependent Variable}

This study focuses on team performance. We measured the total points won for every game by each team at the end of the season, divided by the points they could have earned potentially if they had won all their games, then multiplying this figure by 100 . We carried out the same calculation at the middle of the season.

\section{Independent Variables}

The 9-item Trust Questionnaire developed by McAllister (1995) and adapted to sports settings by Dirks (2000) was used to assess coach and team members' perception of their trust in teammates (8 items) and trust in coach (9 items). We modified this scale by adjusting the referent person to "players / teammates" or "head coach" depending on whether respondents were assessing teammates or their head coach. Respondents indicated how much they agreed or disagreed with 
each statement on a nine-point Likert-scale ranging from 1 (strongly disagree) to 9 (strongly agree). Cronbach's alphas for these two instruments at the individual level were .83 and .92 , respectively. Sample items on these assessments included: "If I share my problems with team players, I know they would respond constructively and with care" and "I would feel a sense of loss if the coach left to take a job elsewhere."

To assess Trust in top management, the 4-item subscale developed by Tzafrir and Dolan (2004) was used. Respondents indicated whether they agreed or disagreed with each statement using a nine-point scale ranging from 1 (strongly disagree) to 9 (strongly agree). This scale measured the perceived (individual) reliability and concern of top management. Cronbach's alpha for this instrument was .87. Sample items included the statements: "The club keeps the promises it makes" and "The actions the club takes are consistent with its words."

We then used a modified version of the Group Environment Questionnaire (Carron, Widmeyer, \& Brawley, 1985) to measure players' perceptions regarding team cohesion (task and social). Consistent with the critique of how cohesion is conceptualized (specially, in terms of the interpersonal attraction to the group, see Hogg et al., 2004), only the 9 items from the two subscales called "group integration task" and "social group integration" were selected and eventually aggregated into a single dimension. This is due to our wanting to capture the groups' feelings about the task and social-oriented correspondence, nearness and ties within the team as a single unit. Respondents indicated how much they agreed or disagreed on a nine-point Likert scale ranging from 1 (strongly disagree) to 9 (strongly agree). Cronbach's alpha for this instrument at the individual level was .81. Sample items included: "Our team is united in trying to reach its performance goals" and "Members of our team would rather go out on their own than go out together as a team." A confirmatory factor analysis (CFA) was also performed at the individual level for this reduced scale of team cohesion as one single factor. The modified scale provided a 
good fit for this data: $\chi^{2}=129.403(27 d f), \mathrm{CFI}=.929, \mathrm{GFI}=.956, \mathrm{TLI}=.906, \mathrm{REMSA}=.074$, $p=.000$.

\section{Control Variables}

Several contextual factors pertaining to team performance in professional sports were identified as control variables. These were based on the focus group discussion as well as on existing literature (Brown, Farrell \& Zorn, 2007; Mullen, \& Copper, 1994; Ryska, Yin, Cooley, \& Ginn, 1999; Webber \& Donahue, 2001). The control variables included in this study were: "Type of sport", "previous match performance" (win/loss in the match prior to filling in the questionnaire), "permanence" (the average number of seasons on the team), "seasons trained by coach" (time that the team has been under the orders of the head coach), "age" (the average age of the team members), and "diversity" (number of team nationalities). Notice that, in keeping with previous research (Hirst, 2009; Hyatt \& Ruddy, 1997), except for seasons trained by coach and permanence on the team, no significant correlation between these control variables and the dependent variable (team performance) was found at the team level of analysis. Finally, we selected the control variable "seasons trained by coach" because it was the only one that did not present differences between sports samples: $F(3,46.70)=2.07, p=.117$; the Brown-Forsythe Robust Test of Equality of Means shows no significant differences; a single homogeneous subset sample was displayed for the seasons trained by coach variable.

\section{Confirmatory Factor Analysis}

In order to check the possibility of mono-method bias, two extra confirmatory factor analyses (CFA) were employed using Amos 16. The first was performed at the individual level of analysis for the totality of the 21 items which constituted the three foci of team trust: Trust in teammates, trust in coach, and trust in top management (8, 9 and 4 items, respectively). According to the CFA 
results, the three-factor structure was acceptable. The CFA yielded an acceptable fit level, but with a relatively high $\chi^{2}=666.23(186 d f)$, Comparison Fit Index $(\mathrm{CFI})=.874$, Tucker-Lewis Index (TLI )$=.844$, and Root Mean Square Error of Approximation $($ RMSEA $)=.087$. In order to validate the three-factor structure, an additional CFA was conducted in which all items were allowed to load on one factor, meaning that all inter-factor correlations were forced to be 1 . The CFA yielded an unacceptable fit level, with $\chi^{2}=2102.26(189 d f), \mathrm{CFI}=.499, \mathrm{TLI}=.398$, and $\mathrm{RMSEA}=.172$. Comparison between these fit indexes as well as the chi-square difference test $\left(\Delta \chi^{2}=1436.03\right.$, $p=.000$ ) suggested that the three-factor model for trust foci provided a better fit to the data (Byrne, 2001).

The second CFA was performed at the team level of analysis in order to determine empirically whether team cohesion and trust in teammates are two different constructs. The two model factor solution produced a fit index of $\chi^{2}=501.59(118 d f), \mathrm{CFI}=.898, \mathrm{GFI}=.910, \mathrm{TLI}=.882, \mathrm{RMSEA}=$ $.069, p=.000$, while the hypothesized one-factor model resulted in $\chi^{2}=228.44(119 d f), \mathrm{CFI}=.866$, $\mathrm{GFI}=.688, \mathrm{TLI}=.847, \mathrm{RMSEA}=.126, p=.000$. Results from the significance chi-square differences test $\left(\Delta \chi^{2}=273.15, p=.000\right)$ suggest that the two-factor model provides a better fit to this data (Byrme, 2001), suggesting that these two constructs perform a differentiated role.

\section{Results}

Table 2 presents the means, standard deviations, reliability coefficients, and correlations for the research variables. The scales show good levels of reliability, with Cronbach alpha coefficients above the .75 level (Nunnally, 1978) both at the individual level of analysis and at the team level of aggregation. The pattern of relation among variables was similar in both samples. The correlation between team performance and team cohesion was approximately $.30(p<.05)$ for both samples. Trust in teammates was positively related to performance measures, ranging from .30 to $.35(p<.05)$ 
in both subsamples and trust in top management $.28(p<.05)$. In general, these findings are consistent with trends revealed in the literature about the positive relationship between trust and performance (Costa 2003; Schippers, 2003). Nevertheless, the relationship between trust in the coach and performance, and trust in top management and team cohesion were not significant. Our findings also indicate that the relationship between trust in the coach and team cohesion was .37 $(p<.01)$ and $.30(p<.05)$ and that trust in teammates and team cohesion was around $.81(p<.01)$. The latter correlation, trust in teammates and team cohesion, is an interesting one, but not surprising considering that trust has been found to be an antecedent for the related construct of cohesion and team efforts (Dirks, 1999) and cooperative behaviour (Morgan \& Hunt, 1994). As previously mentioned, we used different sources for each construct in order to avoid the possibility of common method issues.

Insert Table 2 about here

A Structural Equation Modeling (SEM) analysis of 59 teams was then undertaken using the AMOS statistical program (version 16). The SEM approach was selected as the methodology because of the advantages it provides over multiple regression. These advantages include the desirability of testing models globally rather than coefficients individually, SEM's ability to model mediating variables rather than being restricted to an additive model as in regression, its modeling of error terms, testing of coefficients across multiple between-subjects groups, and the desirability of its strategy comparing alternative models to assess the relative model fit (Garson, 2008).

Prior to evaluating specific direct or indirect relationships, we carried out a test on the overall fit of the entire conceptual model. Here the question was not about individual paths but, rather, how the conceptual model as a whole fit with the sample data. A good fit suggests that we have specified a model that is consistent with the data, while a not "true" model is one that is plausible for the current sample. At the group level of analysis, we tested and evaluated the fit of the research initial model shown in Figure 1 above. This initial model was found to not fit the data. 
We conducted further analyses in an effort to improve the fit of the hypothesized model. To identify the most significant and meaningful modifications, we examined modification indexes and freed paths that were most likely to improve the fit of the model and which made theoretical sense. ${ }^{2}$

Insert Figure 2 about here

The findings of the SEM analysis are presented in Figures 2 and 3, respectively. They suggest only partial support for our stated hypotheses. Only results from the final path diagrams are shown, first for the hypothesized model and then for the modified models. The statistics of the overall fit model are presented in Table 3 which summarizes the fit index results for the path models. As can be seen in the latter, the initial model did not fit the data especially well (i.e., the Goodness of Fit Index (GFI) and Comparison Fit Index $(\mathrm{CFI})<.92$; Adjusted Goodness of Fit Index $(\mathrm{AGFI})<.83$; and Root Mean Squared Error Approximation (RMSEA)>.100).

Insert Table 3 about here

The high correlation found between trust in other team players and team cohesion (both represented within team dynamic relationships) required testing the possible interchangeability between them in the proposed model. Several additional structural equation models were carried out and confirmed via the other split sample. We compared several models with each construct and also created a second order factor for team cohesion and trust in team players. The resulting path models (Figure 3) substantially improved the fit indices: $\chi^{2}=11.1(10 d f), \mathrm{CFI}=.99, \mathrm{GFI}=.93, \mathrm{AGFI}=.88$,

\footnotetext{
${ }^{2}$ Many SEM experts warn against purely empirically-driven model trimming (MacCallum, Roznowski, \& Necowitz, 1992). We were highly aware of this fact when switching from a confirmatory to a more exploratory application of SEM. We tried to keep the essence of the initial theory intact by maintaining the core idea of team experience contribution to performance. All adjustments were made via single-degree freedom tests (freeing a parameter at a time); $\chi^{2}$ difference tests were conducted to ensure that trimming had not incurred too high a cost in terms of fit (the final model is more parsimonious but provides a statistically equivalent fit to the initial model).
} 
RMSEA $=.043$. The same pattern can be seen with the confirmatory model carried out on the other half of the sample: $\chi^{2}=8.34(10 d f), \mathrm{CFI}=1.0, \mathrm{GFI}=.96, \mathrm{AGFI}=.91 \mathrm{RMSEA}=.000$.

The direct effects and statistical significance tests are presented in path figures. The final model which is also displayed in Figure 3 was found to fit the data adequately. The rationale for using this new model is that it preserves the multi-foci approach that creates and maintains trust within the team. In addition, Trust in teammates is now the variable which plays the primary mediation role versus Team cohesion as originally hypothesized. However, Team cohesion still plays a mediating role for Trust in coach and Trust in teammates.

Insert Figure 3 about here

Examination of the standardized regression estimate weights indicates that all the variables except for seasons trained by coach were significant. These results support most of our hypotheses. Specifically, a statistically significant parameter estimate was found for the path between top management trust and trust in teammates $(\beta=.18 ; p<.01)$, for the path between trust in coach and team cohesion $(\beta=.37 ; p<.01)$ and between team cohesion and trust in teammates $(\beta=.82 ; p<.01)$ As expected, the within-team dynamics represented by trust in teammates had a positive impact on team performance $(\beta=.35 ; p<.01)$. AMOS displayed a squared multiple correlation for each variable (Byrne, 2001). Thus, taking into account path model results (see Figures 2 and 3), we can corroborate hypotheses $\mathrm{H1a}$ and $\mathrm{H} 1 \mathrm{~b}$ (Trust in coach and Trust in teammates are positively related to cohesion) and $\mathrm{H} 2$ (Team cohesion is related to performance). Unexpectedly, however, H1c (Trust in top management) and $\mathrm{H} 3$ (the mediation role of cohesion) were not confirmed. However, we did find a positive relationship between Trust in top management and Trust in Teammates $(\beta=.18$; $p<.01)$ 


\section{Testing for Mediation}

Using Model 3, we tested for the fit of two overall mediation paths: i) Trust in teammates as a mediator between Team cohesion and Team performance; and ii) team cohesion as a mediator between Trust in coach and Trust in teammates. The first mediation only resulted in an indirect path because one of the mediation conditions was not met (i.e., the direct path between the predictor and outcome was not significant, albeit the fact that Sobel Test result was significant $(z=2.67, p<.01)$. However, the indirect effect of cohesion on performance through trust in teammates was significant (Preacher \& Leonardelli, 2003).

The assessment of the second path did show full mediation. When testing the fit of overall model (X-M-Y) paths with mediator (X-M and $\mathrm{M}-\mathrm{Y})$ and the direct path $(\mathrm{X}-\mathrm{Y})$, our results indicated that all paths were significant. When there is a mediation effect, the addition of the X-M and $\mathrm{X}-\mathrm{Y}$ paths to the constraint model should not improve the fit. In other words, the previous significance of the X-M and X-Y paths become insignificant when the mediator is taken into account (this SEM process is analogous to Baron and Kelly's regression approach, 1986). The Sobel Test also indicated that cohesion $(z=2.91, p<.01)$ was a significant mediator for the influence of Trust in coach on Trust in teammates.

The final model also explains a reasonable amount of variance in performance outcomes $(12 \%$ for objective team performance). The variance explained in the mediating variables of trust is high. This may not be surprising given the contextual and procedural factors that might influence the perceptions among team players. Multi foci trust variables together with cohesion explained 71 percent of the variance in the relationship dynamics within the team. All subsequent results and the ensuing discussion are based on this final derived model.

Lastly, the integration of all these findings suggests that trust and its three foci are important for the functioning of groups in organizations, and contribute, albeit indirectly, to their performance. 


\section{Discussion}

This study has tested the direct and indirect relationships between three foci of trust and team performance. Our findings confirm that these relationships work in a rather complex manner; the dynamic relationship within the teams, represented as team cohesion and trust in other team players, mediates the relationship between the perceptions of team trust (in top management and trust in the coach) along with the team's overall performance. This finding is different from the mediation originally hypothesized. Our findings, however, do corroborate the multiple targets of the trust construct in organizations, and that high levels of team trust are related to team performance with both direct and indirect effects. Finally, they also demonstrate that trust in leadership (direct management and top management) has a different relationship with performance than originally hypothesized.

\section{Team Trust}

While earlier research on trust has focused primarily on the direct effects of trust on individual, team, and organizational performance (Collins \& Smith, 2006; Tzafrir, 2005), the results of our study suggest that the relationship is more complex than just a simple direct relationship. It has long been assumed that a high level of trust is related to better performance in organizations or teams, though how this occurs is less clear. Consistent with the results reported elsewhere (Dirks, 1999; Costa, 2003; Webber, 2008), this study provides empirical support for the statement that trust within teams allows members to work cooperatively towards achieving organizational goals and add value to their organization (McKnight, et al., 1998; Schippers, 2003).

This pattern of results leads us to suggest that, at least in the context of interactive sports teams, researchers must take into account trust as an exchange mechanism when predicting team performance. Many theories of trust are, in fact, based on exchange theory (Whitener et al., 1998). 
The latter assumes that trust arises from repeated exchanges between different parties (Blau, 1964). As Lewis and Weigert (1985, p. 971) assert, "when we see others acting in a way that implies that they are trusting us, we become more disposed to engage in reciprocal behaviors of trust towards them. Conversely, we usually do not trust people whose actions appear to breach our trust or who do not trust us." Thus, one possible justification for an increase in the cohesion and trust within the team is rooted in the norm of reciprocity (Gouldner, 1960). This implies that we help and do things for others who help and do things for us. In doing so, team members reduce inappropriate behaviour and work towards the attainment of collective goals.

In addition to the exchanged reciprocity, we should also consider other mechanisms that might indicate the relevance of trust while studying social interaction in the sports context. Due to the fact that this research examines trust in different foci (in colleagues, in the manager, and in the organization), performance might also be due to the effect of members' inference about overall team cohesion and team trust. Attribution theory explores how individuals "attribute" causes to events and how this cognitive perception affects their motivation and behaviours and use this to make judgments (Heider, 1958; Kelley, 1973). Therefore, trust may serve as information to make inferences about different social and workplace behaviour, thereby influencing the judgment individuals make. In this way, trust appears to be a reliable cognitive process through which past action becomes future action. In the present study, team members may perceive the team's present effectiveness and will probably (correctly or otherwise) attribute this action to several sources such as top management, the head coach, and their fellow players. Team members may, therefore, make judgments about future behaviour and attitudes from such attributions and may be more willing to trust their teammates, coach, and the institution. Our results, nevertheless, demonstrate that the united relationship within the team is a key variable to increase or decrease the team's performance. Nonetheless, these results should be considered with caution due to the small sample size or perhaps 
to the fact that our measures did not provide enough variation between the relevant variables (team cohesion and team trust).

\section{Trust in Leadership}

Our findings reveal a different pattern from the hypothesized relationships, specifically in terms of the direct effects of some trust targets and also with respect to the mediation role played by team cohesion. One interesting and unexpected finding is the fact that we do not find a direct relationship between Trust in coach and performance nor between Team cohesion and Trust in top management. These results could be explained from both a statistical and conceptual point of view.

Statistically, one could argue that these weak relations could be a matter of artifact because of the high correlation between the Trust in teammates and Team cohesion variables. However, it is through these combined measures that Trust in coach exerts an influence on performance. Thus, Team cohesion and Trust in teammates has a mediation role between Trust in coach and the team's final performance. In terms of Trust in top management, only Trust in teammates mediates its relation with performance

On the other hand, we can use different conceptual explanations to elucidate these unexpected findings. First, Trust in coach is probably the result of a more individualistic focus and behaviour in terms of the interpersonal relationship between players and the coach. This is similar to other constructs in management literature such as citizenship behaviour (Podsakoff, MacKenzie, Paine \& Bachrach, 2000) where individually-directed behaviour is distinguished from organizationallydirected behaviour. We can reasonably infer that the role played by the direct manager leads to benefits for the team process, whereas the role played by top management may benefit the team but 
it specially affects the organization. ${ }^{3}$ Another plausible explanation concerns the different level of the phenomena. Team cohesion is part of the group process, while Trust in top management is part of organizational interaction. However, both processes make a positive contribution to the level of interaction within the team. This can be appreciated in the high degree of variance explained by trust, though they are not linked to one another.

The key role played by team management has been dealt with implicitly in the literature on team performance (Guzzo \& Salas, 1995; Hackman, 1987). Within a sports context, Dirks (2000) reported that trust in the coach amongst basketball players channeled the team's energy towards the roles specified by the latter and eventually lead to the application of his strategies and to better team performance. Thus, trust in the coach is important because it encourages the team to be willing to accept the leader, his/her actions, goals and decisions, and to work harder to attain the communicated objectives. The findings reported here confirm the importance of trust in the leader. However, the link between trust in leadership and effectiveness do not appear to be direct.

Finally, the aim of this study was to examine team performance via an organizational model of trust. Examining how organizational trust has an impact on performance over time has important conceptual, methodological, and practical implications. First, from a conceptual perspective, we can learn more about team dynamics by examining the influence of different levels of trust over time. Second, from a methodological perspective, a quasi-longitudinal approach and the path analysis techniques used herein allow researchers to draw conclusions about dependency. Lastly, from a practical perspective, it is useful to know whether trust has long-term effects within teams. To

\footnotetext{
3 As suggested by an anonymous reviewer, the different measures to assess trust in the coach and in top management may be a concern due to the different patterns of association and their antecedents. These different patterns of association might also be due to a wording-based phenomenon. However, in the context of sports settings, the main coach and top management play conceptually different roles within the organization (e.g., a more strategic role versus a more operative one). It is possible for employees to trust their direct manager but not trust top management (or vice versa). Some authors suggest that trust in top management is not based on the direct relationship between trustor and trustee but on how organizational systems work and the appropriateness of strategic decisions. By contrast, trust in direct managers (the coach) is based more on observed actions and behaviour (McCauley \& Kuhnert, 1992; Costigan, Ilter, \& Berman, 1998; Creed \& Milles, 1996).
} 
summarize, the findings regarding a high level of trust provide an explanation of why, in a context such as the focus of this study, it is likely that teams with trustworthy relationships will perform better. High levels of team trust increase the likelihood of better team performance.

In fact, given that in top professional sports teams all players possess technical competences of the highest level, it is plausible that what makes the difference in terms of the team's overall performance is the synergy and cooperation between the team as a whole rather than the individual technical skills of each single player (Beal et al., 2003). Managers, coaches and sportsman can achieve organizational goals more effectively if they cooperate and generate behaviours of mutual trust. We propose that the costs associated to "deficits in trust" are enormous.

\section{Conclusions, Limitations and Future Research}

From the outset, this study has aimed to evaluate the phenomenon of trust at the team level as a multiple-target construct, paying attention to its relationship to team performance as a function of the cohesion among team members. Our findings reveal the significance the work environment has for team performance. Environments that foment clarity, reliability, concern for others, and openness, and in which there is a relatively high degree of harmony and cohesion among the players and the other actors have the potential to improve their performance. By contrast, environments in which players do not trust each other, the coach, or top management will likely have poorer results.

\section{Theoretical Implications}

The results of this study provide additional support to the growing body of empirical literature on trust within organizations by contributing to the theory of social exchange to help describe work relationships. The major contribution of this study is that multi-foci trust explains team members' relationships and their relative contribution to the organization's overall performance. In fact, the 
relationship between trust and its interaction with the other variables considered in this study suggest that the three different targets of trust are important for how groups function within organizations.

While trust is generally considered an individual phenomenon, it is also possible to understand it at the organizational level (Atkinson \& Butcher, 2003). Organizational trust has to do with the employees believing in the achievement of corporate objectives and trusting their managers so long as these lead to actions which are beneficial for the employees (Kim \& Mauborgne, 1993). Organizational trust has to do with managers' attitudes and behaviours since they contribute through their managerial practices to gauge the levels of global trust (Creed \& Milles, 1996).

\section{Practical Implications}

Several practical implications arise from this study. The results obtained may help managers to better understand how trust is constituted within organizations. They may also foment interventions that strengthen and encourage interpersonal links between the different actors and promote interpersonal behaviours of trust. They may also stimulate cooperative behaviour instead of competitiveness by promoting organizational policies and social norms that ensure interdependence and links between team members.

The study provides further support to the contention that high levels of trust within teams facilitate team cohesion which in turn leads to better performance. Management and organizations must therefore stimulate multi-foci trust in their members. Management should strive to find a way to create and maintain the mechanisms that make this possible within the organization. This mechanism could be achieved by sending reliable messages, taking the various actors' interests into account, and building and developing team trustworthiness (Tzafrir \& Dolan, 2004).

\section{Strengths, Limitations and Boundary Conditions}


In order to avoid an over-reliance on cross-sectional work, we have used a quasi-longitudinal design for this study, where data on the dependent variables comes from objective sources collected retrospectively. In addition, we split each team into two halves and examine different measures in each group as well as use a CFA test. The fact that the Trust in teammates variable was highly correlated to team cohesion is an important finding. We could say that this represents a similar construct or even a possible problem in the measurement tool's sensitivity. Nevertheless, we have used a validated construct as well as different sources for each of the constructs. However, our study has not solved the problem of causal ambiguity in terms of which comes first, performance or trust (Staw, 1975).

Regardless, the group level of analysis provides a more coherent perspective to assess the dynamic of interdependent team processes and it provides a level of explanation more suitable for the phenomenon under study. That notwithstanding, we only gathered data from 690 players on 59 different teams resulting in a relatively small sample. Despite participation by $89 \%$ of the population in these interactive and professional teams and within this specific context (top sports teams), examining this phenomenon among a larger sample would be ideal. Further research will serve to corroborate the consistency of these findings.

The mechanism or construct that mediates the relationship between employees' attitudes and organizational performance is a matter of debate, and researchers have not yet reached agreement on the subject. Thus, exploring this phenomenon further could become a key issue in organizational life. Our research focuses on trust as an informal mechanism to improve performance. How the level of organizational trust impacts performance is a very interesting path for future research.

It is also important to note that the use of sports teams as a target group in this study implies some limitations in terms of external validity. Generalizing these findings to other sectors should be done with caution. There are obvious differences between sports teams and other organizational 
teams in terms of how resources are measured and relationships between members are maintained, though, a full discussion of these issues is beyond the scope of this article. However, as Wright, Smart, and McMahan (1995) assert, both share some common traits: They exist in highly competitive environments with well-established measures of performance, and both types of organizations have people who make decisions and choose and implement strategies to enhance their competitiveness.

\section{Acknowledgements}

An early version of this paper was presented at the 2008 Academy of Management meeting in Anaheim, CA, USA. The authors would like to thank Xavier Suriol for his participation in the study and help with the field work. The authors would also like to thank the senior and associate editors of the Journal of Occupational and Organizational Psychology as well as anonymous reviewers for providing invaluable comments in finalizing this manuscript. Portions of this manuscript were completed while the first author was a visiting research fellow at John Molson School of Business, Concordia University, Montreal, Canada. 


\section{References}

Atkinson, S., \& Butcher, D. (2003). Trust in managerial relationships. Journal of Managerial Psychology, $18,282-304$.

Aubert, B. A., \& Kelsey, B. L. (2003). Further understanding of trust and performance in virtual teams. Small Group Research, 34, 575-618.

Baron, R. M., \& Kenny, D. A. (1986). The moderator-mediator variable distinction in social psychological research: Conceptual, strategic, and statistical considerations. Journal of Personality and Social Psychology, 51, 1173-1182.

Barrick, M. R., Bradley, B. H., Kristof-Brown, A.L., \& Colbert, A.L. (2007). The moderating role of top management team interdependence: Implications for real teams and working groups. Academy of Management Journal, 50, 544-557.

Beal, D. J., Cohen, R. R., Burke, M. J., \& McLendon, C. L. (2003). Cohesion and performance in groups: A meta-analytic clarification of construct relations. Journal of Applied Psychology, 88, 989-1004.

Blau, P. M. (1964). Exchange and power in social life. New York: Wiley.

Brower, H. H., Lester, S. W., Korsgaard, M. A., \& Dineen, B. R. (2009). A Closer Look at Trust Between Managers and Subordinates: Understanding the Effects of Both Trusting and Being Trusted on Subordinate Outcomes. Journal of Management, 35, 327-347.

Brown, T., Farrell, K. A, \& Zorn, T. (2007). Performance Measurement \& Matching: The Market for Football Coaches. Quarterly Journal of Business and Economics, 46, 21-35.

Byrne, B.M. (2001). Structural equations modeling with AMOS. Mahwah, N.J: Lawrence Erlbaum Associates.

Calnan, M., \& Rowe, R. (2007). Trust and Health Care. Sociology Compass, 1, 283-308.

Carron, A.V. \& Bray, S.R. (2002). Team cohesion and team success in sport. Journal of Sport Sciences, 20 , $119-226$.

Carron, A.V., Brawley, L.R., \& Widmeyer, W.N. (1998). The measurement of cohesiveness in sport groups. In J. L. Duda (Ed.), Advances in sport and exercise psychology measurement, 213-226. Morgantown, WV: Fitness Information Technology.

Carron, A. V., Colman, M. M., Wheeler, J., \& Stevens, D. (2002). Cohesion and performance in sport: A meta-analysis. Journal of Sport \& Exercise Psychology, 24, 168-188.

Carron, A. V., Widmeyer, W. N., \& Brawley, L. R. (1985). The development of an instrument to assess cohesion in sport teams: The group environment questionnaire. Journal of Sport Psychology, 7, 244266.

Chansler, P., Swamidass, P., \& Cammann, C. (2003). Self-Managing Work Teams. Small Group Research, $34,101-120$.

Collins, C. J., \& Smith, K. G. (2006). Knowledge exchange and combination: The role of human resource practices in the performance of high-technology firms. Academy of Management Journal, 49, 544-560.

Costa, A.C . (2003). Work team trust and effectiveness. Personnel Review, 32, 605-622.

Costa, A. C., Roe, R. A., \& Taillieu, T. (2001). Trust within teams: The relation with performance effectiveness. European Journal of Work and Organizational Psychology, 10, 225-244.

Costigan, R. D., Ilter, S. S., \& Berman J. J. (1998). A multi-dimensional study of trust in organizations. Journal of Managerial Issues, 10, 303-317.

Creed, W. D., \& Miles, R. E. (1996). Trust in organizations: a conceptual framework linking organizational forms, managerial philosophies, and the opportunity costs of control. In R. M. Kramer, \& T. R. Tyler (Eds.), Trust in Organizations: Frontiers of Theory and Research, (pp. 16-38). London: Sage.

Cropanzano, R., \& Mitchell, M. (2007). Social Exchange theory: An interdisciplinary review, Journal of Management, 31, 874-900. 
Cropanzano, R., Prehar, C., \& Chen, P. (2002). Using Social Exchange theory to distinguish procedural from interactional justice. Group \& Organizational Management, 27, 324-351.

Davis, J. H., Schoorman, F. D., Mayer, R. C., \& Tan, H. H. (2000). The trusted general manager and business unit performance: Empirical evidence of a competitive advantage. Strategic Management Journal, 21, 563-576.

De Vries, M. F. R. (1999). High-performance teams: Lessons from the pygmies. Organizational Dynamics, 27, 66-77.

Dietz, G., \& Den Hartog, D. N. (2006). Measuring trust inside organizations. Personnel Review, 35, 557588.

Dirks, K. T. (1999). The effects of interpersonal trust on work group performance. Journal of Applied Psychology, 84, 445-455.

Dirks, K. T. (2000). Trust in leadership and team performance: evidence from NCAA basketball. Journal of Applied Psychology, 85, 1004-1012.

Dirks, K. T., \& Ferrin, D.L. (2002). Trust in leadership: Meta-analytic findings and implications for research and practice. Journal of Applied Psychology, 87, 611-628.

Dirks, K. T., \& Skarlicki, D. P. (2009). The Relationship Between Being Perceived as Trustworthy by Coworkers and Individual Performance. Journal of Management, 35, 136-157.

Emerson, R. M. (1976). Social Exchange Theory. Annual Review of Sociology 2, 335-362.

Fiore, S. M., Salas, E., \& Cannon-Bowers, J. A. (2001). Group dynamics and shared mental model development. In M. London (Ed.), How people evaluate others in organizations, (pp. 309-336). Mahwah, NJ: Lawrence Erlbaum Associates.

Fontayne, P., Heuze, J. P., \& Raimbault, N. (2006). Relationships between cohesion, collective efficacy and performance in professional basketball teams. Journal of Sport Sciences, 24, 59-68.

Gardner, E., Shields, D. L., Bredemeier. B. J., \& Bostrom, A. (1996). The relationship between perceived coaching behaviours and team cohesion among baseball and softball players. Sport Psychologist 10, $367-381$.

Gambetta, D. (1988). Trust: Making and breaking cooperative relations. New York, NY: Basil Blackwell.

Garson, G. D. (2008). Online class notes for PA765. Retrieved from http://faculty.chass.ncsu.edu/garson/PA765/structur.htm, Nov., 26, 2008.

Gilbert, J. A., \& Tang, T. L. (1998). An examination of organizational trust antecedents. Public personnel Management, 27, 321-338.

Gillespie, N., \& Dietz, G. (2005). Trust repair after an organization-level failure. Paper presented at EIASM (European Institute for Advanced Studies in Management), Amsterdam.

Gould, D., Guinan, D., Greenleaf, C., Medbery, R., \& Peterson, K. (1999). Factors affecting Olympic performance: Perceptions of athletes and coaches from more and less successful teams. The Sport Psychologist, 13, 371-394.

Gouldner, A. W. (1960). The norm of reciprocity: A preliminary statement. American Sociological Review, $25,161-179$.

Grieve, F. G, Whelan, J. P, \& Meyers, A. W. (2000). An experimental examination of the cohesionperformance relationship in an interactive team sport. Journal of Applied Sport Psychology, 12, 219 235.

Grossman, P., Wineburg, S., \& Woolworth, S. (2001). Toward a theory of teacher community. Teachers College Record, 103, 942-1012.

Guzzo, R. A., \& Salas, E. (1995). Team effectiveness and decision making in organizations. San Francisco, CA: Jossey-Bass. 
Hackman, J. R., \& Morris, C. G. (1975). Group tasks, group interaction process, and group performance effectiveness: A review and proposed integration. In L. Berkowitz (Ed.), Advances in experimental social psychology, (Vol. 8, pp. 45-99). New-York: Academic Press.

Hackman, J. R. (1987). The design of work teams. In J. W. Lorsch (Ed.), Handbook of organizational behavio, (pp. 315-342). New York: Prentice-Hall.

Hansen, M., Morrow, J. L., \& Batista, J. (2002). The impact of trust on cooperative membership retention, performance, and satisfaction: an exploratory study. International Food and Agribusiness Management Review, 5, 41-59.

Heider, F. (1958).The Psychology of Interpersonal Behavior. New York: Wiley.

Hempel, P. S., Zhang, Z., \& Tjosvold,D (2009). Conflict management between and within teams for trusting relationships and performance in China. Journal of Organizational Behavior, 30, 41-65.

Hirst, G. (2009). Effects of membership change on open discussion and team performance: The moderating role of team tenure. European Journal of Work and Organizational Psychology, 18, 231-249.

Hyatt, D. E., \& Ruddy, T. M. (1997). An examination of the relationship between work group characteristics and performance: Once more into the breach. Personnel Psychology, 50, 553-585.

Hogg, M. A., Abrams, D., Otten, S., \& Hinkle, S. (2004). The Social identify perspective: intergroup relation, self-conception, and small group. Small Group Research, 35, 246-276.

James, L. R., Demaree, R. G., \& Wolf, G. (1984). Estimating within-group inter-rater reliability with and without response bias. Journal of Applied Psychology, 69, 85-98.

Katz, N. (2001). Sports teams as a model for workplace teams: Lessons and liabilities. Academy of Management Executive, 15, 56-69.

Kelley, H. H. (1973). The processes of casual attribution. American Psychology. 28, 107-128.

Kim, W. C., \& Mauborgne, R. A. (1993). Procedural justice, attitudes, and subsidiary top management compliance with multinationals' corporate strategic decisions. Academy of Management Journal, 36, 502-526.

Konovsky, M. A., \& Pugh, D. S. (1994). Citizenship behavior and social exchange. Academy of Management Journal, 37, 656-669.

Kozlowski, S. W. J., \& Hattrup, K. (1992). A disagreement about within-group agreement: Disentangling issues of consistency versus consensus. Journal of Applied Psychology, 77, 161-167.

Kramer, R. (1999). Trust and distrust in organizations: Emerging perspectives, enduring questions. Annual Review of Psychology, 50, 569-598.

Lane, C. (1998). Introduction: Theories and issues in the study of trust. In C. Lane, \& R. Bachmann, (Eds.), Trust within and between organizations. Conceptual issues and empirical applications, (pp. 1-30). Oxford: Oxford University Press.

Langfred, C. W. (2004). Too much of a good thing? Negative effects of high trust and individual autonomy in self-managing teams. Academy of Management Journal, 47, 385-399.

Langfred, C. W (2007). The downside of self-management: A longitudinal study of the effects of conflict on trust, autonomy, and task interdependence in self-managing teams Academy of Management Journal, 50, 885-900.

Lawler, E. E. (1992). The ultimate advantage: Creating the high involvement organization. San Francisco: Jossey-Bass.

Lewicki, R. J., McAllister, D. J., \& Bies, R. J. (1998). Trust and distrust: New relationships and realities. Academy of Management Review, 23, 438-458.

Lewicki, R., Tomlinson, E., \& Gillespie, N. (2006). Model of interpersonal trust Development: Theorethical approaches, empirical evidences, and future directions. Journal of Management, 32, 991-1022.

Lewis, J. D., \& Weigert, A. (1985). Trust as a social reality. Social Forces, 63, 967-985. 
Lo, S., \& Aryee, S. (2003). Psychological contract breach in a Chinese context: An integrative approach. Journal of Management Studies, 40, 1005-1020.

Loughead, T. M., Colman, M. M., \& Carron, A. V. (2001). Investigating the mediational relationship of leadership, class cohesion and adherence in an exercise setting. Small Group Research, 32, 558-575.

Luria, G. (2008). Climate strength-How leaders form consensus. Leadership Quarterly, 19, 42-53.

Mayer, R. C., \& Davis, J. H. (1999). The effect of the performance appraisal system on trust for management: A field quasi-experiment. Journal of Applied Psychology, 84, 123-136.

Mayer, R. C., Davis, J. H., \& Schoorman, F. D. (1995). An integrative model of organizational trust. Academy of Management Review, 20, 709-734.

McAllister, D. J. (1995). Affect and cognition-based trust as foundations for interpersonal cooperation in organizations. Academy of Management Journal, 38, 24-59.

McCauley, D. P., \& Kuhnert, K. W. (1992). A theoretical review and empirical investigation of employee trust in management. Public Administration Quarterly, 16, 265-285.

MacCallum, R. C, Roznowski, M., \& Necowitz, L. B. (1992). Model modifications in covariance structure analysis: The problem of capitalization on chance. Psychological Bulletin, 111, 490-504.

McGraw, K. O., \& Wong, S.P. (1996). Forming inferences about some intraclass correlation coefficients. Psychological Methods, 1, 30-46.

McKnight, H. D., Cummings, L. L., \& Chervany, N. L. (1998). Initial trust formation in new organizational relationship. Academy of Management Review, 23, 473-490.

Morgan, R. M., \& Hunt, S. D. (1994). The commitment-trust theory of relationship marketing. Journal of Marketing, 58, 20-38.

Mullen, B., \& Copper, C. (1994). The relation between group cohesiveness and performance: An integration. Psychological Bulletin, 115, 210-227.

Nunnally, J. C. (1978). Psychometric theory. New York: McGraw-Hill.

Organ, D. W., Podsakoff, P. M., \& MacKenzie, S. B. (2006). Organizational citizenship behaviours: Its nature, antecedents and consequences. Thousand Oaks, Sage.

Podsakoff, P. M., MacKenzie, S. B., Paine, J. B., \& Bachrach, D. G. (2000). Organizational citizenship behaviors: A critical review of the theoretical and empirical literature and suggestions for future research. Journal of Management, 26, 513-563.

Preacher, K. J., \& Leonardelli, G. J. (2003). Calculation for the Sobel Test: An interactive calculation tool for mediation tests. Retrieved April 27, 2007, from http://people.ku.edu/ preacher/sobel/sobel.htm

Rotter, J. B., (1971) Generalized expectancies for interpersonal trust. American Psychologist, 26, 443-452.

Rousseau, D. (1985). Issues of level in organizational research: Multilevel and cross-level perspectives. Research in Organizational Behavior, 7, 1-37.

Rousseau, M. T., Stikin, S. B., Burt, S. B., \& Carmerer, C. (1998). Not so different after all: Acrossdiscipline view of trust. Academy of Management Review, 23, 393-404.

Ryska, T. A., Yin, Z., Cooley, D., \& Ginn, R. (1999). Developing team cohesion: A comparison of cognitive-behavioral strategies of U.S. and Australian sport coaches. Journal of Psychology, 133, 523539.

Saavedra, R., Earley, P. C., \& Van Dyne, L. (1993). Complex interdependence in task-performing groups. Journal of Applied Psychology, 78, 61-72.

Salas, E., \& Fiore, S. M. (2004). Why team cognition? An overview. In E. Salas, S.M. Fiore (Eds.), Team cognition: Understanding the factors that drive process and performance, (pp. 3-8). Washington, DC: American Psychological Association.

Schippers, M. C. (2003). Reflexivity in Teams. Ridderkerk: Ridderprint.

Shockley-Zalabak, P., Ellis, K., \& Winograd, G. (2000). Organizational trust: What it is, why it matters. 
Organization Development Journal, 18, 35-48.

Simons, T. L., \& Peterson, R. S. (2000). Task conflict and relationship conflict in top management teams: The pivotal role of intragroup trust. Journal of Applied Psychology, 85, 102-111.

Slater, M. R., \& Sewell, D. F. (1994). An examination of the cohesion-performance relationship in university hockey teams. Journal of Sports Sciences, 12, 423-431.

Smith, J. B., \& Barclay, W. B. (1997). The effects of organizational differences and trust on the effectiveness of selling partner relationships. Journal of Marketing, 61, 3-21.

Staw, B. M. (1975). Attribution of the "causes" of performance: A general alternative interpretation of crosssectional research on organizations. Organizational Behavior \& Human Performance, 13, 414-432.

Thau, S., Crossley, C., Bennett, R., \& Sczesny, S. (2007). The relationship between trust, attachment, and antisocial work behaviours. Human Relations. 60, 1155-1179.

Turman, P. D. (2003). Coaches and Cohesion: The impact of coaching techniques on team cohesion in the small group sport setting. Journal of Sport Behavior, 26, 86-103.

Tzafrir, S., \& Dolan, S. (2004). Trust me. A scale for measuring manager-employee trust. Management Research, 2, 117-134.

Tzafrir, S. (2005). The relationship between trust, HRM practices and firm performance. International Journal of Human Resource Management, 16, 1600-1622.

Webber, S. S. (2008). Development of Cognitive and Affective Trust in Teams. A Longitudinal Study. Small Group Research, 39, 746-769.

Webber, S. S., \& Donahue, L. M. (2001). Impact of highly and less job-related diversity on work group cohesion and performance: A meta-analysis. Journal of Management, 27, 141-162.

Weick, K. E.; Roberts, K. H. (1993). Collective mind in organizations: Heedful interrelating on flight decks. Administrative Science Quarterly, 38, 357-381.

Westre, K. R., \& Weiss, M. R. (1991). The relationship between perceived coaching behaviors and group cohesion in high school football teams. The Sport Psychologist, 5, 41-54.

Whitener, E. M., Brodt, S. E., Korsgaard, A., \& Werner, J. M. (1998). Managers as initiators of trust: An exchange relationship framework for understanding managerial trustworthy behavior. Academy of Management Review, 23, 513-530.

Wright, P., Gardner, T., \& Moynihan, L. (2003). The impact of HR practices on the performance of business units. Human Resource Management Journal, 13, 21-36.

Wright, P. M., Smart, D. L., \& McMahan, G. C. (1995). Matches between human resources and strategy among NCAA basketball teams. Academy of Management Journal, 38, 1052-1074.

Zucker, L. G. (1986). Production of trust: Institutional sources of economic structure 1840-1920. In B.M. Staw, \& L. L. Cummings (Eds.), Research in Organizational Behavior: (pp. 53-111). Greenwich, CT: JAI Press. 
Table 1. Sample: Descriptive Statistics by Team, According to Type of Sport ( $n=690$ players).

\begin{tabular}{|c|c|c|c|c|c|c|c|c|c|c|c|}
\hline & \multirow{2}{*}{$\begin{array}{c}\text { No. of } \\
\text { teams }\end{array}$} & \multicolumn{2}{|c|}{$\begin{array}{c}\text { Average player } \\
\text { age }\end{array}$} & \multicolumn{2}{|c|}{$\begin{array}{c}\text { Size of Team } \\
\text { (Members per } \\
\text { team) }\end{array}$} & $\begin{array}{c}\text { Permanence } \\
\text { (Seasons on } \\
\text { the same } \\
\text { team) }\end{array}$ & \multicolumn{2}{|c|}{$\begin{array}{c}\text { Tenure with } \\
\text { the Coach } \\
\text { (seasons) }\end{array}$} & \multicolumn{2}{|c|}{$\begin{array}{c}\text { Number of } \\
\text { Nationalities } \\
\text { within Teams }\end{array}$} \\
\cline { 3 - 13 } & Mean & $S D$ & Mean & $S D$ & Mean & $S D$ & Mean & $S D$ & Mean & $S D$ \\
\hline Hockey & 16 & 24.6 & 1.5 & 9.9 & 0.7 & 4.1 & 1.6 & 1.9 & 1.0 & 1.4 & 0.6 \\
\hline $\begin{array}{c}\text { Indoor } \\
\text { Football }\end{array}$ & 16 & 26.0 & 1.6 & 11.4 & 1.75 & 3.4 & 1.2 & 1.7 & 0.9 & 2.3 & 0.6 \\
\hline Handball & 15 & 25.1 & 1.4 & 14.5 & 2 & 3.6 & 0.7 & 2.1 & 1.0 & 4.7 & 1.8 \\
\hline Basketball & 12 & 26.4 & 1.2 & 10.9 & 1.2 & 3 & 1.6 & 1.5 & 0.7 & 4.8 & 1.2 \\
\hline Total $=$ & 59 & 25.5 & 1.6 & 11.7 & 2.3 & 3.6 & 1.4 & 1.81 & 0.9 & 3.2 & 0.6 \\
\hline
\end{tabular}

Table 2. Means, Standard Deviations, and Correlations ${ }^{\mathrm{a}} \mathrm{b}(n=59$ teams).

\begin{tabular}{|c|c|c|c|c|c|c|c|c|}
\hline \multirow[t]{2}{*}{ Variables: } & & & 1 & 2 & 3 & 4 & 5 & 6 \\
\hline & Mean $^{\mathrm{c}}$ & $S D^{\mathrm{c}}$ & & & & & & \\
\hline Mean $^{\mathrm{c}}$ & & & 46.46 & 5,99 & 6.02 & 6.37 & 6.76 & 1.80 \\
\hline$S D^{\mathrm{c}}$ & & & 18.54 & 1.02 & 1.27 & 1.46 & .86 & .60 \\
\hline 1. Team Performance & 46.46 & 18.54 & & $.30^{*}$ & $.28 *$ & -.01 & $.30^{*}$ & $.26^{*}$ \\
\hline 2. Team Cohesion & 5.99 & 1.07 & $.28^{*}$ & & .13 & $.45^{* *}$ & $.81^{* *}$ & .21 \\
\hline 3. Trust in Top Management & 6.03 & 1.19 & $.28^{*}$ & .13 & & -.01 & $.29 *$ & .02 \\
\hline 4. Trust in Coach & 6.36 & 1.35 & .00 & $.37 * *$ & -.01 & & $.39 * *$ & -.01 \\
\hline 5. Trust in Teammates & 6.77 & .82 & $.35^{* *}$ & $.82 * *$ & $.29 *$ & $.39 * *$ & & .20 \\
\hline 6. Seasons trained by Coach & 1.8 & .60 & $.26^{*}$ & $.28^{*}$ & .02 & -.09 & .20 & \\
\hline
\end{tabular}

${ }^{a}$ Correlations for half sample (cohesion measure taken from the first half sample, and trust measures from the second) are shown above the main diagonal. Correlations for the second half (cohesion measure taken from the second half sample and trust measures from the first) are shown below the main diagonal.

$\mathrm{b} * p<.05 ; * * p<.01$.

${ }^{\mathrm{c}}$ Means and Standard Deviation for the first half sample are displayed in the horizontal axis, and for the second half sample in the vertical axis. 
Table 3. Goodness-of-Fit Results for Hypothesized and Derived Models ( $n=59$ teams).

\begin{tabular}{|c|c|c|c|}
\hline Goodness-of-Fit & $\begin{array}{c}\text { Hypothesized } \\
\text { model }\end{array}$ & $\begin{array}{c}\text { Derived } \\
\text { model }\end{array}$ & $\begin{array}{c}\text { Confirmatory } \\
\text { model }\end{array}$ \\
\hline Chi-squared & 16495 & 11.082 & 8.335 \\
\hline df & 10 & 10 & 10 \\
\hline p & .086 & .351 & .596 \\
\hline CFI & .925 & .990 & .000 \\
\hline GFI & .918 & .944 & .909 \\
\hline AGFI & .827 & .883 & .000 \\
\hline RMSEA & .106 & .043 & .909 \\
\hline
\end{tabular}

Note: $d f=$ Degrees of freedom; $p=$ Probability level; GFI = Goodness of Fit Index;

$\mathrm{CFI}=$ Comparative Fit Index; RMSEA= Root Mean Squared Error of Approximation

Figure 1. Tri-foci Trust Model.

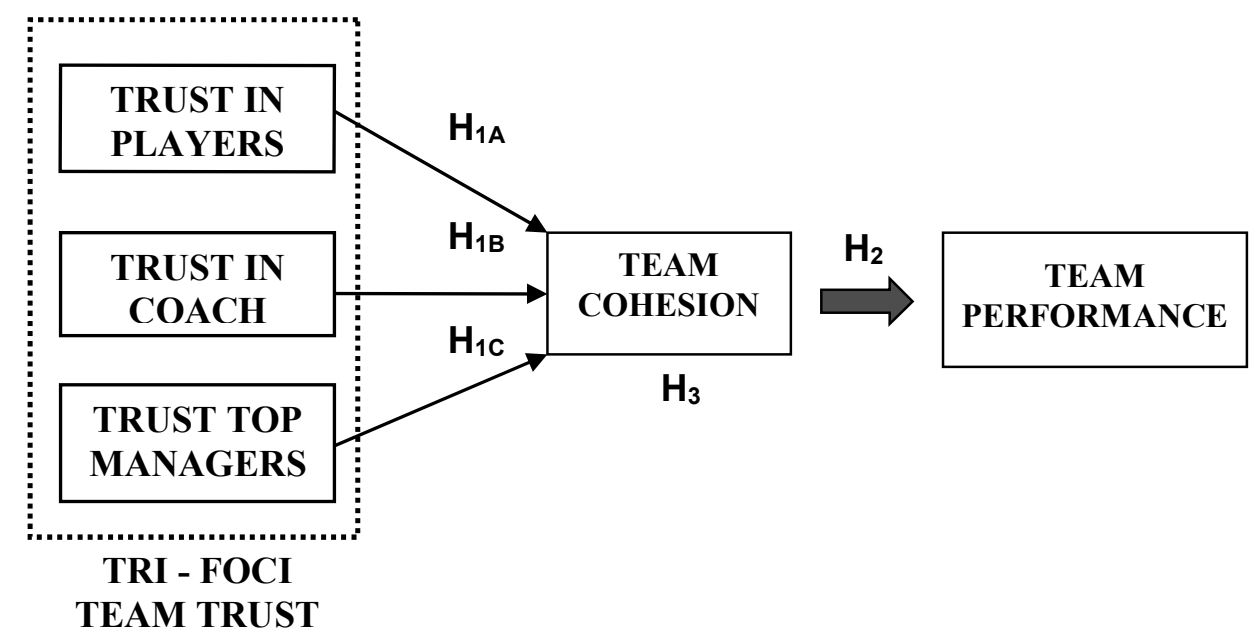


Figure 2. SEM Results for the Initial Research Trust Model a ${ }^{\text {a }}$

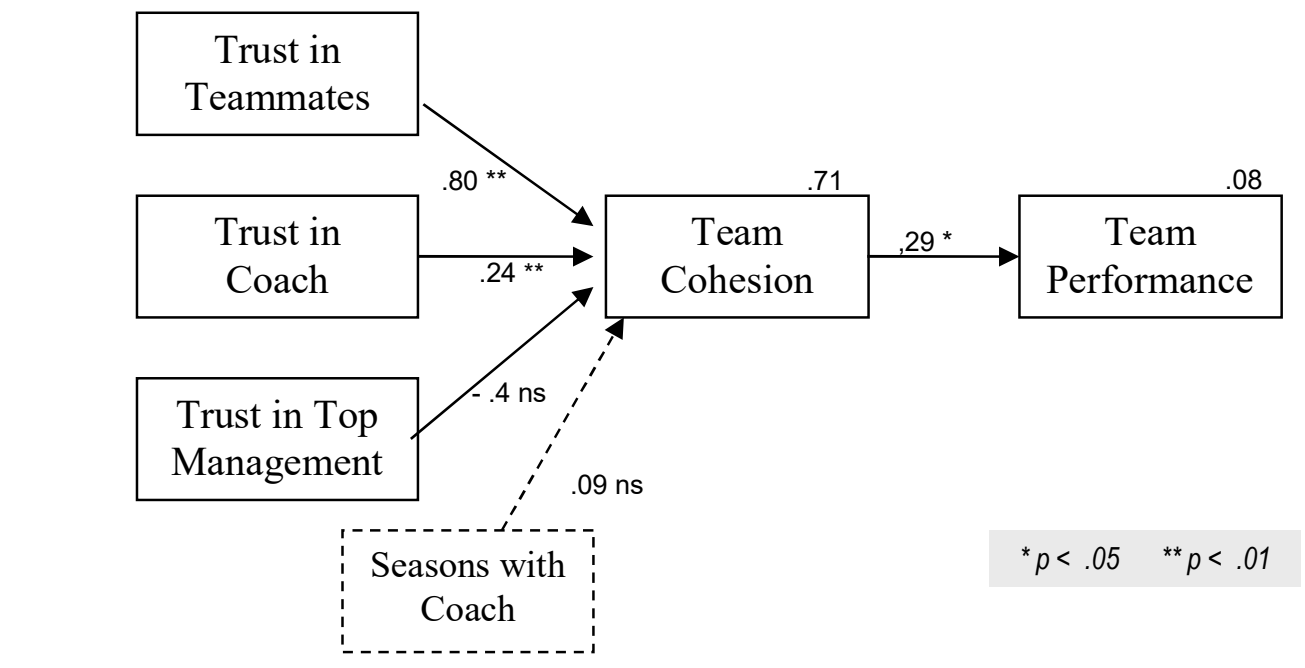

a Note: Path coefficients are standardized.

Figure 3. SEM Results for the Derived Model ${ }^{\mathrm{a}}$.

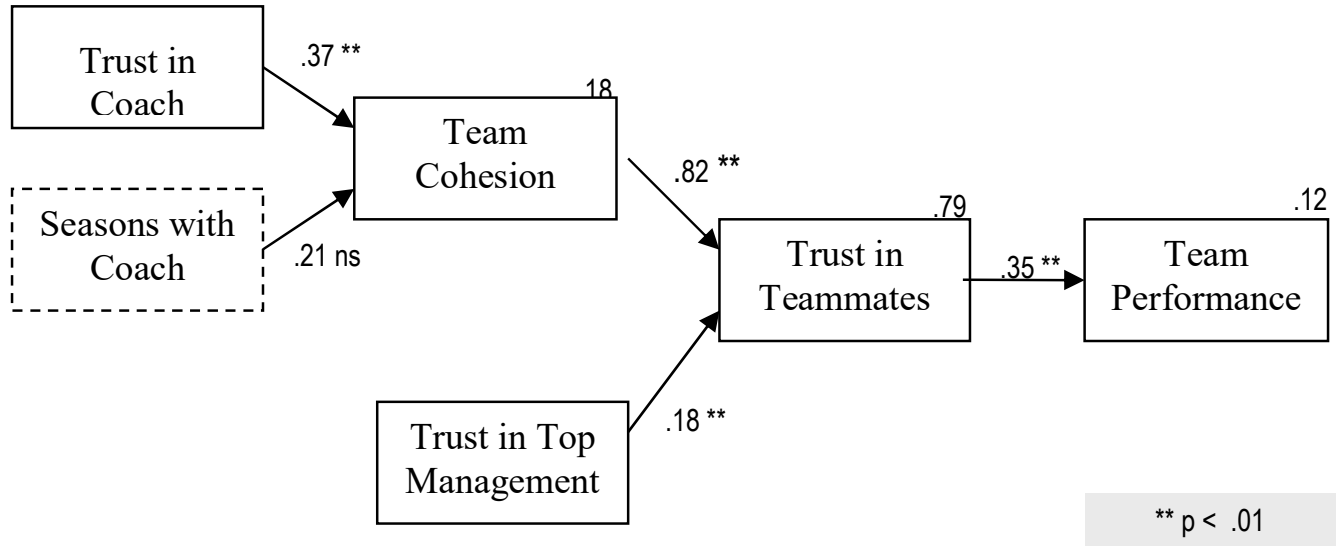

${ }^{a}$ Note: Path coefficients are standardized. 